\title{
Evaluation of the healing effects of Onosma bolbutrichum root extract on second degree burn wound in rabbit
}

\author{
Aliasghar Hemmati ${ }^{1}$, Anahita Rezaie ${ }^{2}$, Pari Tamri $^{3 *}$, Sadegh Yousefinasab ${ }^{1}$ \\ ${ }^{1}$ Department of Pharmacology and Toxicology, School of Pharmacy and Physiology Research Center, Jundishapur University of Medical Sciences, \\ Ahvaz, Iran. ${ }^{2}$ Department of Pathobiology, School of Veterinary Medicine, Shahid Chamran University of Ahvaz, Ahvaz, Iran. \\ ${ }^{3}$ Department of Pharmacology and Toxicology, School of Pharmacy, Hamadan University of Medical Sciences, Hamadan, Iran.
}

\section{ARTICLE INFO}

Article history:

Received on: 10/06/2017

Accepted on: 17/07/2017

Available online: 30/11/2017

Key words:

Burn, Rabbit, Onosma

bolbutrichum, Root extract.

\begin{abstract}
Objective: Burn injury is one of the main causes of death by injury worldwide and healing of burn is still a challenge in modern medicine. In present study we investigated the healing effects of n-hexanedichloromethane (1:1) extract of Onosma bulbotrichum roots on second degree burn wound in rabbit.
\end{abstract}

Methods: 36 Iranian rabbits were used in this study. The rabbits were randomly divided into 6 groups. After creating of standard second degree burn wound on the back of rabbits, different treatment modalities were investigated in six groups. Group 1 received no treatment, group 2 was treated with cold cream (vehicle), group 3,4 and 5 were treated with creams containing $0.5 \%, 1 \%$ and $2 \%(\mathrm{~W} / \mathrm{W})$ of plant extract, respectively. The 6 th group served as standard group and was treated with Silver Sulfadiazine. Healing was assessed by the rate of wound healing, and total collagen content of treated skin samples. Histopathological evaluation of wound samples was also performed.

Results: The cream containing $0.5 \%$ (W/W) of Onosma bulbotrichum root extract significantly $(P<0.01)$ increased the rate of wound contraction and tissue collagen and non-collagenous proteins content when compared to vehicle and no- treatment groups. Additionally, histopathological evaluation confirmed these results.

Conclusion: The results of this study indicated that Onosma bulbotrichum root extract has the potential for treatment of burn wound and it can be used to treat different types of wounds in human beings also.

\section{INTRODUCTION}

A burn is a type of injury to skin, or other tissues, caused by heat, cold, electricity, chemicals, friction, or radiation (Shlash et al., 2016). Skin is one of the most important organs of human body since it performs an array of various vital functions. Protection from harmful materials in the external environment, defense against microorganisms, fluid, protein and electrolyte homeostasis, thermoregulation, neurosensory and

\footnotetext{
* Corresponding Author

Pari Tamri, Department of Pharmacology and Toxicology, School of Pharmacy, Hamadan University of Medical Sciences, Hamadan, Iran.Tel: 081-38381594,E-mail: p.tamri@ umsha.ac.ir
}

metabolism are some of the most important functions which are performed by the skin (Tortora, 1993). A burn injury results in either the loss or disruption of some or all of these functions. The burn injuries are among the leading causes of disability and mortality resulting large costs in health care system all over the world (Rowan et al., 2015). The healing of burn wounds is a complex process including: inflammation, neo-vascularization, granulation tissue formation, re-epithelialization and wound contraction (Hettiaratchy and Dziewulski, 2004).

Although various treatment options are available for burn wounds management, but further research is required for identifying novel targets and treatment paradigms to further improve burn wound care. Medicinal plants have been used in the treatment of burns for centuries almost in all cultures worldwide and play an 
important role in managing skin disorder (Bahramsoltani et al., 2014).

Iranians have long used plant remedies in the treatment of many diseases. Thousands of years of history and hundreds of books have placed Iranian traditional medicine among the oldest and richest alternative medicines(Sahranavard et al., 2014).

Onosma bolbutrichum (Boraginaceae) is a biennial herbaceous plant widely found in western and northern parts of Iran. In traditional medicine genus Onosma L plants are used in the treatment of variety of diseases such as bronchitis, hemorrhoids, wounds, peptic ulcer and hypertension. The plants of genus Onosma L. contains alkannin and shikonin, flavonoids, ferulic and vanillic acids, which may responsible for antiinflammatory, wound healing, analgesic and its antibacterial actions (Kumar et al., 2013).

In Iranian traditional medicine different extracts of root of $O$. bolbutrichum are used topically for the treatment of burns and wounds. Use of these extracts is only based on folklore without any scientific evidence of effectiveness. To determine whether its traditional use are supported by biological effects, the healing effects of n-hexane- dichloromethane (1:1) extract of Onosma bulbotrichum roots on second degree burns was investigated by assessment of some healing parameters and comparing its healing effects to those of Silver sulfadiazine.

\section{MATERIALS AND METHODS}

\section{Plant material}

The plant of Onosma bolbutrichum was collected from the west of Iran (Lorestan province) and identified by the Department of Botany, Faculty of Sciences, Shahid Chamran University of Ahvaz. The roots were separated, washed and dried at room temperature.

\section{Extract preparation}

The dried roots were placed in to blender to be grounded into powder.300g of powdered root was extracted with n-hexane dichloromethane $(1: 1)(250 \mathrm{ml})$ in soxhlet apparatus. The extract was concentrated by rotary vacuum evaporator (Yamato RE300, Japan) and then air dried.

\section{Topical Preparation of root extract of $\boldsymbol{O}$. bolbutrichum}

The creams containing $0.5 \%, 1 \%$ and $2 \%$ weight of extract per weight of cold cream were prepared. Briefly, after weighing, the plant extract was solubilized in a small amount of ethanol $70 \%$, the extract was emulsified in the cream base, by continuous mixing, at room temperature.

\section{Experimental animals}

36 healthy Iranian rabbits (weighing between 2000$2200 \mathrm{~g}$ ) of either sex were used in this study. The animals were housed under standard conditions of temperature $\left(22 \pm 3^{\circ} \mathrm{C}\right)$, relatively humidity $(55 \% \pm 5)$ and light ( $12 \mathrm{~h}$ light/ dark cycles $)$ with adequate supply of food and water ad libitum. All experimental methods were approved by the laboratory animal's ethical committee of the Ahvaz Jundishapur University of Medical Sciences in Ahvaz, Iran, and followed national guidelines for the care and use of laboratory animals (1996, published by National Academy Press, 2101 Constitution Ave. NW, Washington, DC 20055, USA). Rabbits were divided into six equal groups. The control group did not receive any treatment, vehicle group treated with cold cream, treatment groups received different doses of $O$. bolbutrichum root extract (OBRE) ( $0.5 \%, 1 \%$ and $2 \%$ in cold cream, W/W ), respectively, the sixth group was treated with Silver sulfadiazine (SSD) cream1\% (Sobhan Darou Co, Iran) as standard treatment.

\section{Thermal injury model}

Two identical wounds were created on the back of each rabbit, at a distance of more than $2 \mathrm{~cm}$ from each other. The dorsal hairs of rabbits were shaved and the shaved area was disinfected with ethanol $70 \%$ and anesthetized with Lidocaine $2 \%$.Animals were subjected to full-thickness second-degree skin burns with $2.5 \mathrm{~cm}$ surface area diameter by hot plate. The plate was immersed in boiling $\left(100{ }^{\circ} \mathrm{C}\right)$ water until thermal equilibrium was reached. The plate was then placed on the back of the rabbits for 20seconds without applying pressure (Abdullahi et al., 2014). Extracts were topically applied to the wound twice a day.

\section{Wound healing rate}

The wound healing rate was measured as reduction in the wound size. The wounds were photographed every day and the wound area was calculated using Image-J software. The healing percentage of each wound was calculated as below:

$$
\text { wound healing } \%=\frac{\text { Initial wound size }- \text { Specific day wound size }}{\text { Initial wound size }} \times 100
$$

\section{Histopathological evaluation}

Samples were taken for histopathological study with a small excision containing part of the wound area from skin after 10 days of treatment. Samples were fixed in $10 \%$ buffered formalin, processed, blocked with paraffin, then sectioned in to5 $\mu \mathrm{m}$ sections, and stained with hematoxylin and eosin.

\section{Collagen and non-collagenous proteins content assay}

After complete healing of the wounds, total collagen and non-collagenous proteins content of skin samples obtained from experimental groups were determined using Sirius Red/Fast Green Collagen Staining Kit (Chondrex), according to manufacturer's protocol. The tissue sections were $15 \mu \mathrm{m}$ thick, and collagen and non- collagenous proteins were determined in tissue sections.

\section{Statistical analysis}

Results are expressed as mean $\pm \mathrm{SD}$. Data were evaluated using the two-way ANOVA followed by Bonferroniposthoc test. Values of $P<0.05$ were considered as statistically significant. 


\section{RESULTS AND DISCUSSION}

\section{Wound healing rate}

The percentage of wound closure in experimental groups on days 7, 14 and 16 after burn injury are shown in Figure 1. The significant reduction in wound area was observed in the animals treated with SSD and OBRE $0.5 \%$ compared with those who received vehicle or no treatment $(\mathrm{P}<0.01)$ [Figure 2]. Although the wounds treated with SSD healed more quickly (16days) than those which treated with OBRE0.5\% (17 days) but there were no statistically significant differences between two groups. The degree of wound healing did not differ significantly among OBRE $1 \%$, OBRE5\%, vehicle and no treatment groups.

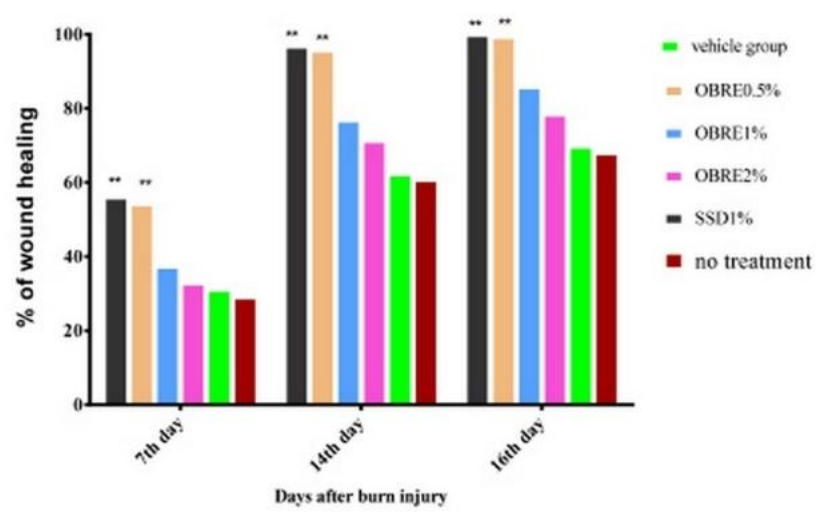

Fig. 1: Percentages of wound healing in experimental groups in day 7,14 and 16 after burn injury. Data are expressed as Mean $\pm \mathrm{SD}, * * \mathrm{P}<0.01$ when compare to no treatment and vehicle groups. SSD: Silver sulfadiazine, OBRE: Onosma bolbutric).

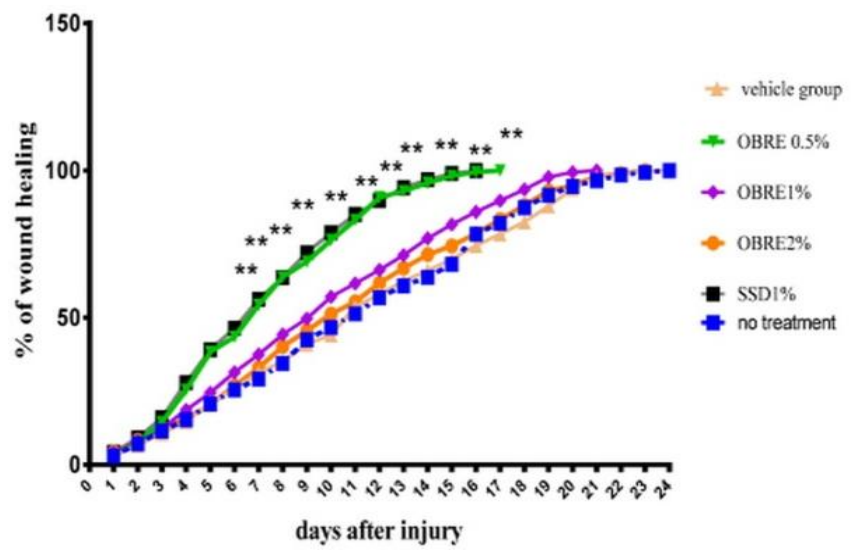

Fig. 2: Effect of Onosma boblutrichum root extract on wound healing rate in second degree burn wound. Data are expressed as Mean $\pm \mathrm{SD}, * * \mathrm{P}<0.01$ when compare to no treatment and vehicle groups. SSD: Silver sulfadiaz).

\section{Histopathological studies}

Histopathalogical features of skin samples obtained from experimental groups on day 10 after burn injury are illustrated in Figure 3.In untreated and vehicle treated wounds, the surface of wounds was covered with exudate, the re-epithelialization was incomplete and the granulation tissue was observed [Figure 3. A \& B], whereas, in SSD and OBRE $0.5 \%$ treated wounds more complete re-epithelialization, little exudate and thick granulation tissue were observed [Figure3.A \& B]. In OBRE1\% and 2\%treated wounds the migrating epithelial cells and granulation tissue were observed. There were inflammatory cells and red blood cells in wound site [Figure3 C \& D].
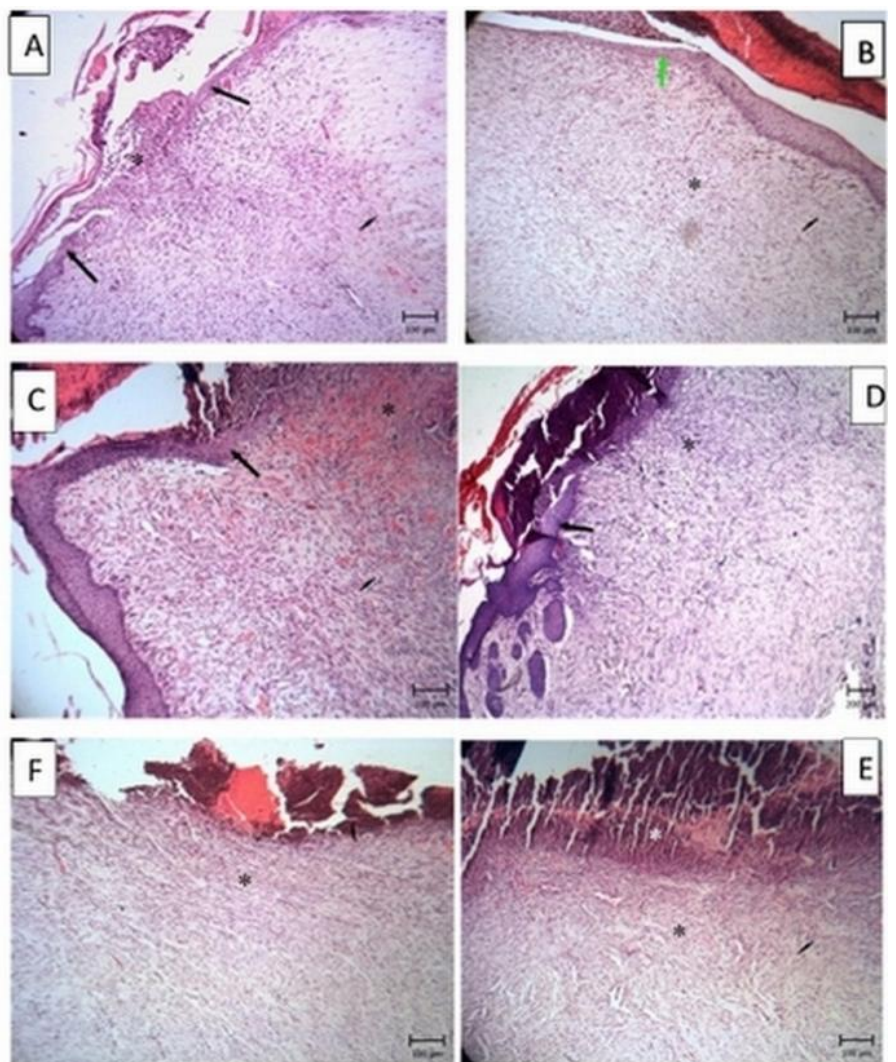

Fig. 3: Histopathological features of skin tissue samples obtained from experimental groups at day 10 after burn injury. A) SSD treated group, B) OBRE $0.5 \%$ treated group, C) OBRE1\% treated group, D) OBRE $2 \%$ treated group, E) Vehicle treated).

\section{Collagen and non-collagenous proteins in tissue samples}

Wounds collagen content significantly $(P<0.01)$ increased in SSD and OBRE0.5\% treated groups after complete healing, when compared to the vehicle treated and no treatment group [Table 1]. The non-collagenous proteins content in SSD, OBRE $0.5 \%$, OBRE $1 \%$ and OBRE2\% treated animals was significantly $(P<0.01)$ higher than that in vehicle treated and untreated animals [Table 2].

Table 1: The collagen content of skin tissue samples of experimental groups after complete wound healing.

\begin{tabular}{cc}
\hline Experimental groups & Collagen content $(\boldsymbol{\mu g} / \mathbf{g}$ tissue $)$ \\
\hline SSD $1 \%$ & $17.917 \pm 0.176^{* *}$ \\
OBRE $0.5 \%$ & $19.150 \pm 0.155^{* *}$ \\
OBRE $1 \%$ & $16.529 \pm 0.183$ \\
OBRE $2 \%$ & $16.197 \pm 0.131$ \\
Cold cream & $9.390 \pm 0.137$ \\
No treatment & $8.641 \pm 0.171$ \\
\hline
\end{tabular}

Data are expressed as Mean $\pm \mathrm{SD}, * * P<0.01$ when compare to cold cream and no treatment groups. OBRE: Onosma bolbutrichum root extract, SSD: Silver Sulfadiazine. 
Table 2: The non-collagenous proteins content of skin tissue sample of experimental groups after complete wound healing.

\begin{tabular}{cc}
\hline Experimental groups & $\begin{array}{c}\text { Non }- \text { collagenous proteins } \\
(\boldsymbol{\mu g} / \mathbf{g} \text { tissue })\end{array}$ \\
\hline SSD 1\% & $295.92 \pm 4.600^{* *}$ \\
OBRE $0.5 \%$ & $285.80 \pm 7.581^{* *}$ \\
OBRE1\% & $278.41 \pm 5.927 * *$ \\
OBRE $2 \%$ & $250.28 \pm 9.00 * *$ \\
Cold cream & $115.18 \pm 4.820$ \\
No treatment & $92.67 \pm 3.080$ \\
\hline
\end{tabular}

Data are expressed as Mean $\pm \mathrm{SD}, * * \mathrm{P}<0.01$ when compare to cold cream and no treatment groups. OBRE: Onosma bolbutrichum root extract, SSD: Silver Sulfadiazine.

Effective treatment of burn wounds remains an important challenge for clinicians and researchers. Plants and their derivatives have the potential for the treatment of burn wounds and evaluation of their efficacy in the treatment of wound injuries is necessary (Mohammadi-Barzelighi et al., 2011). The results of present study demonstrated the wound healing activity of Onosma bolbutrichum root extract, but the involved mechanism is unclear. Many species of Onosma have been studied with respect to their bioactive chemical compounds, because the plants of this genus have been used in traditional medicine to treat variety of diseases(Shahina Naz et al., 2006). Alkannins and shikonins have been found in the external layer of the roots of many species of the Boraginaceae family (Mehrabian et al., 2012, Shahina Naz et al., 2006). Some studies have shown the antioxidant, antibacterial and anti-inflammatory activity of shikonins (Lee et al., 2015, Chen et al., 2001). The inflammatory response is an important part of the wound healing process, but long -term persistence of inflammation is a reason for impaired wound healing(Singer and Clark, 1999). Infection is one of the leading causes of morbidity and mortality in burn patient (Williams et al., 2009). Topical antibacterial agents decrease morbidity and mortality in patient with major burn injuries (Church et al., 2006). Free radicals are necessary for proper healing of skin wounds, but over production of free radicals causes oxidative stress, a condition that weakens immune system, accelerates aging and increases the risk of chronic diseases. Free radicals damage collagen, protein and lipid which are key components of wound healing (Wortsman, 2013). Therefore reducing production of free radicals is essential for proper wound healing. Thus, the healing activity of $O$. bolbutrichum could be partly due to its antioxidant, antibacterial and anti-inflammatory activity.

\section{CONCLUSION}

This study concluded that OBRE extract promote burn wound healing in second degree burns in rabbit and it may be suggested to use for treating burn wounds in human being. However further studies are required to identify and isolation of its active constituents responsible for this pharmacologic effect.

Financial support and sponsorship: This study is from a Pharm D thesis at Ahvaz Jundishapur University of Medical Sciences and was funded by Physiology Research Center of Ahvaz Jundishapur University of Medical sciences (Grant No. PRC119), Ahvaz, Iran).

Conflict of Interests: There are no conflicts of interest.

\section{REFERENCES}

Abdullahi A, Amini-Nik S, Jeschke M G. Animal Models in Burn Research. Cell Mol Life Sci, 2014; 71: 3241-3255

BahramsoltaniR, Farzaei M H, Rahimi R. Medicinal plants and their natural components as future drugs for the treatment of burn wounds: an integrative review. Arch Dermatol Res, 2014; 306: 601-617.

ChenX, Oppenheim J, Howard OM. Shikonin, a component of anti-inflammatory Chinese herbal medicine, selectively blocks chemokine binding to CC chemokine receptor-1. IntImmunopharmacol, 2001; 1: 229236.

Church D, Elsayed S, Reid O, Winston B, Lindsay R. Burn Wound Infections. Clin Microbiol Rev, 2006; 19: 403-434.

Hettiaratchy S, Dziewulski P. ABC of burns: pathophysiology and types of burns. BMJ, 2004; 1: 328.

Kumar N, Kumar R, Kishore K. Onosma L.: A review of phytochemistry and ethnopharmacology. Pharmacogn Rev, 2013; 7: 140151.

Lee YS, Lee DY, Kim YB, Lee SW, Cha SW, Park HW, Han $\mathrm{SH}$, et al. The Mechanism Underlying the Antibacterial Activity of Shikonin against Methicillin-Resistant Staphylococcus aureus. Evid Based Complement Alternat Med, 2015; 2015:1-9.

Mehrabian AR, Sheidai M, Noormohammadi Z, Mozafarian V, Asrei Y. Palynological diversity in the genus Onosma L.(Boraginaceae) of Iran. Ann Biol Res, 2012; 3: 3885-3893.

Mohammadi-Barzelighi $\mathrm{H}$, Alaghehbandan R, Motevallian A, Alinejad F, Soleimanzadeh-Moghadam S, Sattari M, Lari A R. Epidemiology of severe burn injuries in a Tertiary Burn Centre in Tehran, Iran. Ann Burns Fire Disasters, 2011; 24: 59-62.

Naz S, Ahmad S, AjazRl, Sheikh AS, SiddiqiR. Antibacterial activity directed isolation of compounds from Onosma hispidum. Microbiol Res, 2006; 161: 43-48.

Rowan MP, Cancio LC, Elster E A, Burmeister DM, Rose L F, Natesan Sh, Chung, Kevin K et al. Burn wound healing and treatment: review and advancements. Crit Care, 2015; 19: 243-246.

Sahranavard Sh, Ghafari S, Mosaddeg M. Medicinal plants used in Iranian traditional medicine to treat epilepsy. Seizure, 2014; 23: 328 332.

Al Madani Sh, Al Deib JO, El Alsubhi JI, Suliman F, Al Helmi SS, Mohammed Adel A, Javed Akhtar KH, et al. Demographic characteristics and outcome of burn patients requiring skin grafts: a tertiary hospital experience. Int J Burns Trauma, 2016; 6: 30-36.

Singer A J, Clark R A. Cutaneous wound healing. N Engl J Med, 1999; 52: 341

Tortora GJ, Grabowski SR. 1993. Principles of Anatomy and Physiology. New York, USA: HarperCollins College Publishers.

Williams FN, Herndon D N, Hawkins H K, Lee J O, Cox R A, Kulp G A. The leading causes of death after burn injury in a single pediatric burn center. Crit Care, 2009; 13: R183.

Wortsman X. 2013. Dermatologic Ultrasound with Clinical and Histologic Correlations. New York, USA: Springer.

\section{How to cite this article:}

Hemmati A, Rezaie A, Tamri P, Yousefinasab S. Evaluation of the healing effects of Onosma bolbutrichum root extract on seconddegree burn wound in rabbit. J App Pharm Sci, 2017; 7 (11): $168-171$. 